\title{
Envenoming by Crotalid Snake Chinese Moccasin Agkistrodon Acutus Bite - A Case Report
}

\section{Jiří Valenta, Zdeněk Stach, Pavel Michálek}

Department of Anesthesiology and Intensive Care, First Faculty of Medicine, Charles University in Prague and General University Hospital in Prague, Prague, Czech Republic

Received March 4, 2015; Accepted June 1, 2015.

Key words: Snakebite - Agkistrodon acutus - Chinese moccasin - Envenoming Afibrinogenemia

Abstract: Although the bites caused by snakes from former Agkistrodon family in the areas of occurrence are not rare and even have certain epidemiologic importance, in case of envenoming by Deinagkistrodon acutus the clinical studies and case reports are very sporadic. This case report describes the envenoming of a private snake breeder bitten by young Chinese moccasin Deinagkistrodon acutus to the thumb of his left hand. He sought for a medical help immediately after snakebite. Patient presented with a local oedema on the affected limb, extending up to the half of the forearm. Laboratory examinations showed serious haemostatic disturbance with defibrination syndrome, immeasurably prolonged clotting times and extreme elevation of D-dimers. No other obvious clinical symptoms were present. Fibrinogen and fresh frozen plasma were administered because the antivenom was not available immediately. The specific antivenom was urgently imported 22 hours after the bite and administered at a dose of two vials three times until laboratory haemocoagulation parameters returned back to physiological values.

Mailing Address: Jiří Valenta, MD., Department of Anesthesiology and Intensive Care, First Faculty of Medicine, Charles University in Prague and General University Hospital in Prague, U Nemocnice 2, 12808 Prague 2, Czech Republic; e-mail: valenta@vfn.cz 


\section{Introduction}

Chinese moccasin Deinagkistrodon acutus (Figure 1) is representative of the monovalent genus Deiagkistrodon previously ranked into one genus Agkistrodon, crotalid snakes occurring in North and Central America and Asia. D. acutus is native in southeast China, North Vietnam, Laos and Taiwan. Envenoming after snakebites of this genus, including $D$. acutus, has a relatively large epidemiological significance in the areas of occurrence. LD50 of venom ranges from $0.04 \mathrm{mg} / \mathrm{kg} \mathrm{IV} \mathrm{to} 10.0 \mathrm{mg} / \mathrm{kg}$ SC (Brown, 1973).

The venom of this Agkistrodon genus consists mostly of the toxic enzymes. This venom especially contains some components with haemocoagulation effects: prothrombin activators, the components activating additional factors of the plasmatic coagulation system, thrombin-like fibrinogen converting enzymes, direct fibrino(geno)lytic enzymes, platelet-aggregation inhibitors and even platelet activators. Generally, these components are responsible for anticoagulation and procoagulation effects at the same time, which depend rather on the dose of venom. Haemostatic disorder represents fundamentally the most severe symptomatology. This disorder is expressed mainly as defibrination, which is partly result of direct fibrino(geno)lysis and partly caused by DIC-like consumption induced by prothrombin activation, thrombin-like fibrinogen-converting enzymes and other activators of the plasmatic coagulation system. The systemic envenoming is then mostly seen as haemocoagulation disorder with the signs of defibrination in the laboratory parameters and it can progress clinically to haemorrhage and (micro)thrombi formations (Li et al., 2000).

Haemorrhagins and some other components increase capillary permeability, causing inter alia local oedema, sometimes even hypotension due to the capillary leakage.

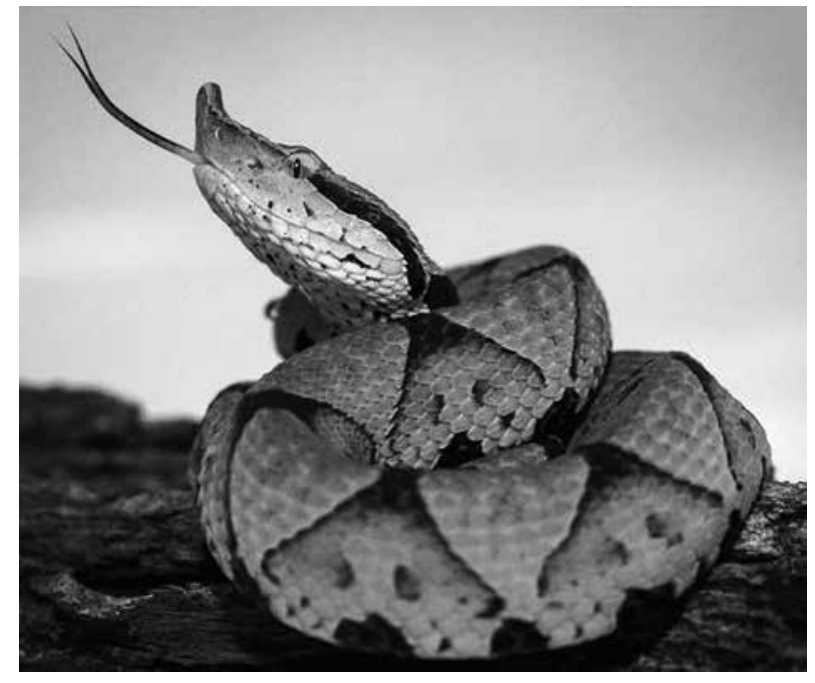

Figure 1 - Deinagkistrodon acutus (photo Jan Dohnal). 
Venom of this species contents sometimes even presynaptic enzymatic neurotoxins with mild clinical effects on the facial muscles only.

Concerning the local infliction, proteolytic and other cytotoxic enzymes are responsible for affecting the tissue. Local necrosis and compartment syndrome can also develop as a part of this envenoming (Warrell, 1995).

\section{Case report}

A Czech-based snake breeding enthusiast, 38-year-old man, suffered snakebite to the thumb of his left hand while handling the Chinese moccasin Dienagkistrodon acutus baby-snake. A significant swelling of the left hand with subsequent extension to a third of the forearm developed immediately. One hour later, he attends the Emergency Room of a General University Hospital. The first laboratory samples were taken 1.5 hours after the bite and did not show any serious pathological

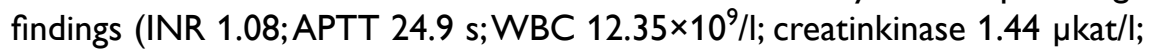
myoglobine $44 \mu \mathrm{g} / \mathrm{l})$. No clinical signs of systemic envenoming were present. The patient was immediately transferred to the Toxinology Center (TC) belonging to the general intensive care unit of the same hospital for observation. Repeated laboratory screening performed 1 hour later showed drop in fibrinogen (FBG), slightly prolonged clotting times and an extremely increased D-dimers (D-dim). Subsequently, within seven hours after the bite, the victim developed afibrinogenaemia, prolonged clotting times to immeasurable values and extreme increase of D-dim (Table 1). The blood count including WBC $\left(8.17 \times 10^{9} /\right)$ and platelets (PLT) $\left(311 \times 10^{9} / l\right)$ were within normal limits. The values of the biochemical laboratory examination were without pathological findings including myoglobin $(57 \mu \mathrm{g} / \mathrm{l})$ and creatinkinase $(3.47 \mu \mathrm{kat} / \mathrm{l})$.

Because the specific antivenom was not available in TC, six vials of specific Deinagkistrodon acutus antivenin Thailand have been urgently imported from abroad (Medical Toxicology Information Services, Guy's Hospital, London, United Kingdom).

Upon detection of afibrinogenemia, 3 units of fresh frozen plasma (FFP) and $1 \mathrm{~g}$ of fibrinogen (FBG) were given. Subsequently, seven hours after the bite, another 6 units of FFP and $2 \mathrm{~g}$ of FBG were administered without any changes in haemocoagulation laboratory parameters.

Acute renal failure, which may occur in similar cases, was prevented by fluid replacement therapy with forced diuresis using $20 \%$ mannitol intravenously and urine alkalinisation by application of acetazolamide and bicarbonate.

First two vials of antivenom were gradually infused in $500 \mathrm{ml}$ saline 22 hours after the snakebite without impact on haemocoagulation parameters. Another 2 vials were administered 5 hours later with effect on increase in FBG level and shortening the clotting times. Two more vials of antivenom administered after following 8 hours furthermore increased FBG level and simultaneously decreased D-dim levels. Close monitoring of haemocoagulation parameters continued until normalization of laboratory parameters (Table 1). Subsequently, swelling of the 
158) Prague Medical Report / Vol. 116 (2015) No. 2, p. 155-160

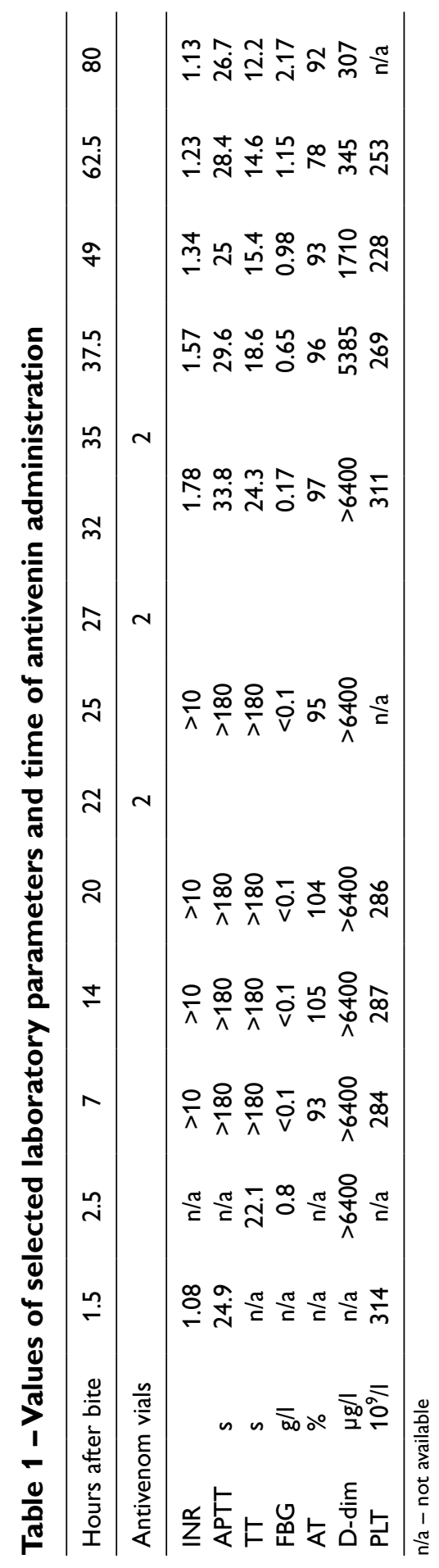


left arm receded to the level of wrist. Patient was discharged home $4^{\text {th }}$ day after snakebite in good medical condition.

During the entire period of afibrinogenaemia the patient didn't show any clinical signs of bleeding and any decrease in PLT count. The parameters of biochemical examinations remained in normal limits.

\section{Discussion}

Deinagkistrodon acutus bites are relatively common at the site of occurrence (Hung, 2004). They represented $6 \%$ of all 64 registered snakebites in the southern Chinese province Guangxi in 1990 (Sawai et al., 1992). However, relevant information about the course of envenoming and detailed clinical descriptions is sparse.

In this described case, the first and main symptom of systemic envenoming, i.e. hypofibrinogenaemia leading then into afibrinogenaemia, was detected 2.5 hours after the bite. Direct fibrino(geno)lysis (Wang et al., 2004) and partly consumptive coagulopathy participated in this process. Consumption cascade can be induced by prothrombin activators and/or directly acting non-inhibited thrombin isoenzymes in snake venom (Tang et al., 2009, 2013). Stationary antithrombin (AT) levels indicate the effect of thrombin-like isoenzymes which are non-inhibitable by AT.The influence of direct fibrino(geno)lysis is not exactly predictable, because the levels of FDP formed by this type of degradation are not routinely quantified. On the other side, high levels of $\mathrm{D}$-dim show degradation of stabilized fibrin polymer and thereby ongoing consumptive disorder.

Venom of D. acutus contains both platelet aggregation activating and inhibiting components. The absence of thrombocytopenia during coagulation disorder represents domination of PLT inhibiting components and thus exclusion of platelets in this type of coagulopathy (Kong et al., 2009; Wang et al., 2014).

Even if afibrinogenaemia is asymptomatic, it can lead to life threatening haemorrhage caused by any minimal injury. This case testifies, that afibrinogenaemia itself does not lead to bleeding necessarily, if an injury is not present.

Repeated administration of FBG and FFP were not effective in normalization of laboratory parameters in this type of haemocoagulation disorder, nevertheless, their positive influence on the clinical status cannot be excluded.

It has been shown that two vials of antivenom were insufficient to neutralize haemocoagulation components of the venom. Subsequently administered two more doses significantly improved the laboratory findings, which then became stable after the administration of last two vials. It is mostly recommended to use higher starting dose of antivenom (Warrell, 1995), but the authors' experience suggest that the gradual titration of antivenom amount can be used. We did not see any complications associated with antivenom application in 17 cases during the period of last 15 years, due to mild prolonging of the venom neutralization time. However, either antivenom allergic reactions or a subsequent serum sickness did not occur. By authors meaning, this is associated just with gradual and fractionated 
administration and lowest effective total dose of administered antivenom (Valenta et al., 2014).

At present, the full recommended dose of $D$. acutus antivenom is not, according to the server www.toxinfo.med.tum.de available in the entire Europe. This fact can result in difficulties to resolve similar cases in the near future.

Our case report may also document the hazard of severe intoxication caused even by baby-snake bites, which are sometimes underestimated, mainly by the community of breeders.

Acknowledgements:The authors thank to doctors Ondrej Kopecky, Michal Porizka, Jan Rulisek, Robert Sachl, Barbora Simanovska, Mykhailo Zakharchenko, for their cooperation during patient treatment.

\section{References}

Brown, J. H. (1973) Toxicology and Pharmacology of Venoms from Poisonous Snakes. Charles C. Thomas, Springfield.

Hung, D. Z. (2004) Taiwan's venomous snakebite: Epidemiological, evolution and geographic differences. Trans. R. Soc. Trop. Med. Hyg. 98, 96-101.

Kong, Y., Huo, J. L., Xu, W., Xiong, J., Li, Y. M., Wu, W.T. (2009) A novel anti-platelet aggregation tripeptide from Agkistrodon acutus venom: isolation and characterization. Toxicon 54, 103-109.

Li, Q. B., Yu, Q. S., Huang, G.W., Tokeshi, Y., Nakamura, M., Kinjoh, K., Kosugi, T (2000) Hemostatic disturbances observed in patients with snakebite in south China. Toxicon 38, 1355-1366.

Sawai, Y., Kawamura, Y., Toriba, M., Kobayashi, T., Wang, N. P., Li, C. B., Li, B.Y., Li, Z. Y., Li, H. P., Tang, S. X. (1992) An epidemiological study on the snakebites in Guangxi Zhuang autonomous region, China in 1990. Snake 24, 1-15.

Tang, S. S., Zhang, J. H., Tang, B. S., Tang, Z. H., Li, H. Z., Yuan, H. J., Chui, S. L., Zhao, E. Y. (2009) Biochemical and hemostatic mechanism of a novel thrombin-like enzyme. Thromb. Res. 124, 631-639.

Tang, S. S., Wang, X. H., Zhang, J. H., Tang, B. S., Qian, L., Li, P.Y., Luo, L. W. (2013) Biochemical properties and comparative pharmacology of a coagulant from Deinagkistrodon acutus snake venom. Eur. J. Pharm. Sci. 49, 90-98.

Valenta, J., Stach, Z., Michalek, P. (2014) Exotic snake bites in the Czech Republic - Epidemiological and clinical aspects during 15-year period (1999-2013). Clin. Toxicol. 52, 258-264.

Wang, Q. Q., Chen, J. S., Liang, X. X., Qiu, P. X., Wang, Y.W., Yan, G. M. (2004) Hemorrhagic activity and mechanism of Flla, a fibrinolytic enzyme from Agkistrodon acutus venom. Acta Pharmacol. Sin. 25, 514-521.

Wang, S., Xu, X., Gao, S., Zhu, S., Rong, R., Li, B. (2014) Purification and partial characterization of a novel fibrinogenase from the venom of Deinagkistrodon acutus: Inhibition of platelet aggregation. Protein Expr. Purif. 99, 99-105.

Warrell, D. A. (1995) Clinical toxicology of snakebite in Asia. In: Handbook of Clinical Toxicology of Animal Venoms and Poisons, eds. Meier, J., White, J., pp. 493-618, CRC Press, Boca Raton. 